\title{
Controle alternativo de helmintos de Astyanax cf. zonatus utilizando fitoterapia com sementes de abóbora (Cucurbita maxima) e mamão (Carica papaya) ${ }^{1}$
}

\author{
Rodrigo Y. Fujimoto ${ }^{2}$, Helrik C. da $\operatorname{Costa}^{3}$ e Fabrício M. Ramos ${ }^{4^{*}}$
}

\begin{abstract}
Fujimoto R.Y., Costa H.C. \& Ramos F.M. 2012. [Alternative control of helminthes, parasites of Astyanax cf. zonatus, using phytotherapy with seeds of Cucurbita maxima and Carica papaya.] Controle alternativo de helmintos de Astyanax cf. zonatus utilizando fitoterapia com sementes de abóbora (Cucurbita maxima) e mamão (Carica papaya). Pesquisa Veterinária Brasileira 32(1):5-10. Laboratório de Parasitologia e Piscicultura, Universidade Federal do Pará, Alameda Leandro Ribeiro s/n, Aldeia, Bragança, PA 68600-000, Brazil. E-mail: fabriciomramos@gmail.com

The objective of this study was to evaluate the effectiveness of an alternative method with pumpkin and papaya seeds, dried and ground, for control of helminth parasites of Astyanax cf. zonatus. Sixty fish were distributed into twelve containers, with one fish/liter. The experiment consisted of four treatments and three replications: $\mathrm{TJ}=$ fish in fasting; TRC = fish fed with commercial diet; TSA = fish fed ad libitum with pumpkin seed, and TSM = fish fed ad libitum with papaya seeds. After seven days of feeding, all fish were weighed and blood was taken for blood smears. Efficacy was determined by checking the presence of parasites in the gills, stomach and intestine, in $40 \%$ of fishes per treatment $(n=6)$. TJ and TSM showed $39 \%$ and $25 \%$ of weight loss respectively. The TSA showed better efficacy against the nematode in intestine and stomach (95.26\% and $92.48 \%)$. The TSM promoted $72 \%$ of efficiency on monogeneans control. Hematology revealed an increase of monocyte values to treatment TSM. A decrease of eosinophil values was observed in treatments TSA, TSM and TRC. Thus, feeding fishes with pumpkin is a effective alternative method of low cost for control of nematodes in Astianax cf. zonatus.
\end{abstract}

INDEX TERMS: Alternative method, treatment, worms, fish, Astyanax cf. zonatus.

RESUMO.- 0 objetivo do trabalho foi avaliar a eficácia de sementes de abóbora e mamão desidratadas e moídas, no controle de helmintos parasitos de Astyanax cf. zonatus. Sessenta peixes foram distribuídos em doze recipientes, um peixe/litro. 0 experimento constituiu de quatro tratamentos e três repetições: $\mathrm{TJ}$ = peixes deixados em jejum; TRC $=$

\footnotetext{
${ }^{1}$ Recebido em 23 de junho de 2011.

Aceito para publicação em 6 de setembro de 2011.

${ }^{2}$ Laboratório de Ictioparasitologia e Piscicultura, Faculdade de Engenharia de Pesca, Universidade Federal do Pará (UFPA), Campus de Bragança, Alameda Leandro Ribeiro s/n, Aldeia, Bragança, PA 68600-000, Brasil.

${ }^{3}$ Pós-Graduando em Doenças Infeccionas e Parasitárias, UFPA, Campus de Belém, PA, Alameda Leandro Ribeiro s/n, Aldeia, Bragança, PA 68600000.

${ }^{4}$ Pós-Graduando em Ciência Animal, Universidade Federal do Pará, Campus de Belém, PA, Alameda Leandro Ribeiro s/n, Aldeia, Bragança, PA 68600-000. Bolsista CNPq (Proc.130166/2010-3). *Autor para correspondência: fabriciomramos@gmail.com
}

peixes alimentados com ração comercial; TSA = peixes alimentados ad libitum com abóbora, e TSM = peixes alimentados ad libitum com mamão. Após sete dias de alimentação, todos os peixes foram pesados, e o sangue foi retirado para extensão sanguínea. A eficácia foi determinada, verificando a presença de parasitos nas brânquias, no estômago e no intestino. Os peixes do TJ e TSM apresentaram perda de peso (39\% e $25 \%$, respectivamente). 0 TSA apresentou melhor eficácia no controle de nematóides do intestino e do estômago (95,26\% e 92,48\%). No controle de monogenéticos TSM promoveu $72 \%$ de eficácia. Na hematologia observou-se aumento de monócitos nos peixes do TSM e os valores de eosinofilos diminuíram nos tratamentos TSA, TSM e TRC. Assim pode-se concluir que a alimentação com abóbora pode ser utilizado como um controle alternativo eficaz de nematóides intestinais do lambari.

TERMOS DE INDEXAÇÃO: Método alternativo, tratamento, verminose, peixe, Astyanax cf. zonatus. 


\section{INTRODUÇÃo}

Os helmintos parasitos de peixes são encontrados com muita frequência tanto em pisciculturas como na natureza. Em pisciculturas, os parasitos branquiais podem causar lesões no epitélio respiratório, e os endoparasitas podem causar espoliações no tegumento intestinal e competir por nutrientes dos alimentos, aumentando os custos de produção e diminuindo as taxas de crescimento. Assim, para o controle destes parasitos muitos produtos químicos são utilizados, por exemplo, o formol (FDA 1992 e 1998), o permanganato de potássio e o sulfato de cobre (Reardon \& Harrell 1990) que são utilizados para controle dos ectoparasitas, e outros produtos como levamizol (Hirazawa et al. 2000) e o mebendazol (Martins et al. 2001) utilizados como endoparasiticidas. Porém a utilização destes produtos possui diversos inconvenientes como o elevado custo de tratamento, possibilidade de resistência do parasito aos princípios ativos e acúmulo de resíduos químicos nos animais tratados (Chagas 2004).

Alternativamente a isso, diversos fitoterápicos podem ser utilizados no tratamento de parasitoses de peixes como o caso do nin (Cruz et al. 2004), o alho (Martins 2004) entre outros, os quais podem ser administrados na forma de banhos ou adicionados à dieta. Essa utilização de fitoterápicos vem ganhando espaço na aqüicultura por possuir diversas vantagens no cultivo como: a diminuição do impacto ambiental, pois esses são produtos biodegradáveis; diminuição dos resíduos químicos nos animais; são potencialmente menos tóxicos por serem menos concentrados; possuem diversos modos de ação, resultando em menor probabilidade de causar resistência além de serem menos onerosos na criação (Coimbra et al. 2006). Muitas plantas são conhecidas popularmente como portadoras de atividade anti-helmínticas, porém em poucos estudos há comprovação científica de suas eficácias, e seus princípios ativos em peixes. Nesse sentido, estão as sementes de abóbora e mamão moídas que são utilizadas popularmente como um tratamento alternativo anti-helmíntico eficaz e barato, porém em peixes existem poucos estudos sobre a sua eficácia, bem como de suas consequências nas variáveis hematológicas. A abóbora e o mamão são utilizados com sucesso como anti-helmínticos por muitas populações de índios (Morais et al. 2005).

Peixes pertencentes ao gênero Astyanax sp. são importantes no ambiente como componentes principais nas dietas de peixes carnívoros, ajudando na manutenção da cadeia trófica (Abdallah et al. 2004, Santin et al. 2005). Além disso, larvas de nematóides podem utilizar esses peixes como hospedeiro intermediário. Esse gênero também tem importância como peixe ornamental e na piscicultura, para comercialização como isca viva (Navarro et al. 2006). A verificação da eficiência da ação das sementes de abóbora e mamão poderia diminuir o custo de produção, tanto no que se refere ao manejo pós-captura de peixes coletados na natureza quanto na piscicultura, além de diminuição do impacto ambiental (Chagas 2004). Assim, os produtores e/ou pescadores deixariam de utilizar produtos químicos de alto custo e também deixariam de lançar resíduos, altamente concentrados, no ambiente sem nenhum tratamento.
A hematologia de peixes é uma ferramenta de fundamental importância para conhecimento das condições biológicas e bioquímicas, normais e patológicas. Muitos estudos demonstraram variações no quadro hematológico dos peixes quando estes estão parasitados, quando são submetidos ao estresse de tratamento ou quando tem sua dieta modificada (Ranzani-Paiva \& Silva-Souza 2004).

Assim pelo exposto acima o objetivo do trabalho foi avaliar a eficácia de sementes de abóbora e mamão desidratadas e moídas, no controle de helmintos parasitos de Astyanax cf. zonatus e a avaliação desta alimentação sobre a contagem diferencial de leucócitos.

\section{MATERIAL E MÉTODOS}

Foram utilizados 60 espécimes de Astyanax cf. zonatus acondicionados em caixas de água de $200 \mathrm{~L}$, naturalmente infectados com helmintos parasitas, no Laboratório de Ictioparasitologia e Piscicultura do Campus Universitário de Bragança-Pará, passando por um período de aclimatação de dez dias. As caixas eram providas de oxigenação constante e trocas de água diária na proporção de $20 \%$ do volume total. Os peixes eram alimentados com ração comercial duas vezes ao dia e a sobra sifonada.

Para alcançar os objetivos proposto utilizou-se um delineamento inteiramente casualizado com quatro tratamentos e três repetições, sendo que os tratamentos eram constituídos por: TJ: peixes estocados e deixados em jejum (controle negativo): TRC: peixes estocados e alimentados com ração comercial (controle positivo); TSA: Peixes estocados e alimentados ad libitum com sementes de abóbora e TSM: peixes estocados e alimentados ad libitum com sementes de mamão. 0 período experimental foi de sete dias.

Para tanto foram utilizados sessenta peixes com peso médio de $0,48 \pm 0,07 \mathrm{~g}$ distribuídos em doze recipientes com cinco litros de água e na densidade de estocagem de um peixe/litro, num sistema semi-estático que consistia em troca de água diária (20\%) e aeração constante.

Os parâmetros de $\mathrm{pH}$, oxigênio dissolvido e temperatura foram monitorados diariamente.

Os peixes foram alimentados ad libitum duas vezes ao dia. Foram observados quanto à aceitação dos alimentos e a presença de sobras. E as dietas consistiam em ração comercial (27\%PB), e sementes de abóbora e mamão desidratadas e moídas de acordo com os tratamentos acima.

As sementes foram secas à sombra, durante três dias e posteriormente moídas de forma que o tamanho fosse compatível com o tamanho da boca dos peixes. Optou-se por fornecer as sementes in natura e não incorporadas a ração devido a praticidade, pois a inclusão em uma dieta seria um manejo a mais para um produtor a campo. Porém utilizou-se o tratamento com ração comercial como controle positivo.

Devido ao tamanho reduzido dos peixes e devido a pouca quantidade de ração utilizada por dia optou-se pelo tratamento dos peixes em jejum para que se pudesse comparar o peso, verificando se existiam diferenças entre o desempenho dos peixes, considerando esse tratamento como um controle negativo.

Anteriormente ao ensaio experimental uma amostra de 10 peixes foi necropsiada para realização da contagem inicial de parasitos nematóides (intestino e estomago) e monogenéticos (brânquias). Para tanto os animais foram sacrificados por aprofundamento do plano anestésico com uso de solução de benzocaína (1g/20 l água). A coleta dos parasitas e contagem foi realizada segundo determinações de Amato et al. (1991). 
Após o período experimental, todos os peixes foram pesados e $40 \%$ dos peixes de cada tratamento $(n=6)$ foram sacrificados e analisados as brânquias, o estômago e o intestino como procedimento acima, verificando a presença e contabilizando in totum os parasitos com auxilio de microscópio óptico (Ghiraldelli et al. 2006). De posse destes dados foi determinada a eficácia de cada tratamento segundo fórmula abaixo:

\section{Eficácia $=\underline{\text { MNPGC }- \text { MNPGT }} \times 100 /$ MNPGC}

Onde: MNPGC: Média do número de parasitas do grupo anterior ao experimento, MNPGT: Média do número de parasitas do grupo tratado

O sangue, devido ao pequeno tamanho dos peixes, era retirado por corte da nadadeira caudal e realizado a extensão sanguínea e posteriormente corada com Rosenfeld (1947) para a contagem diferencial de leucócitos (contagem de 100 leucócitos) segundo metodologia de Tavares-Dias (2000).

\section{Análise estatística}

Após obtenção dos dados estes foram submetidos à análise de variância (ANOVA), assumindo um nível de significância de 1\%. Sendo F significativo foi realizado o teste de Tukey para comparação de médias $(\mathrm{p}=0,05)$. Os dados que não apresentaram distribuição normal foram transformados em arcseno $\sqrt{x}+0,5$, no caso de dados percentuais, e log $\mathrm{x}$ no caso de dados de contagem de parasitas.

\section{Perda de Peso}

\section{A}

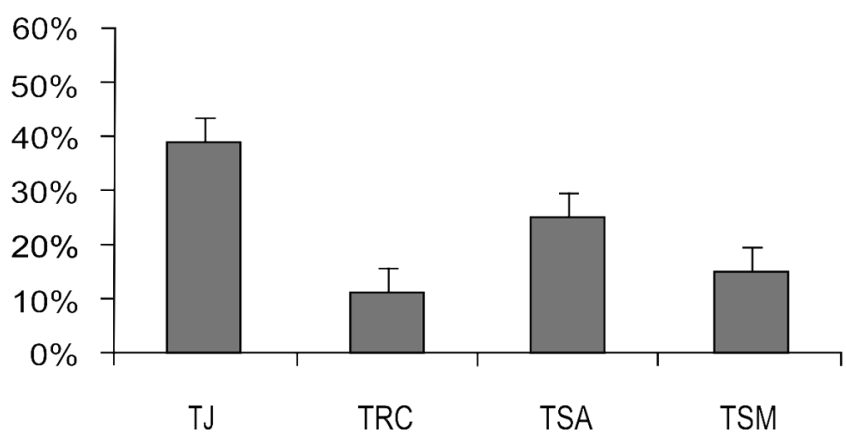

Capillaria sp. e Anisakidae no intestino

C

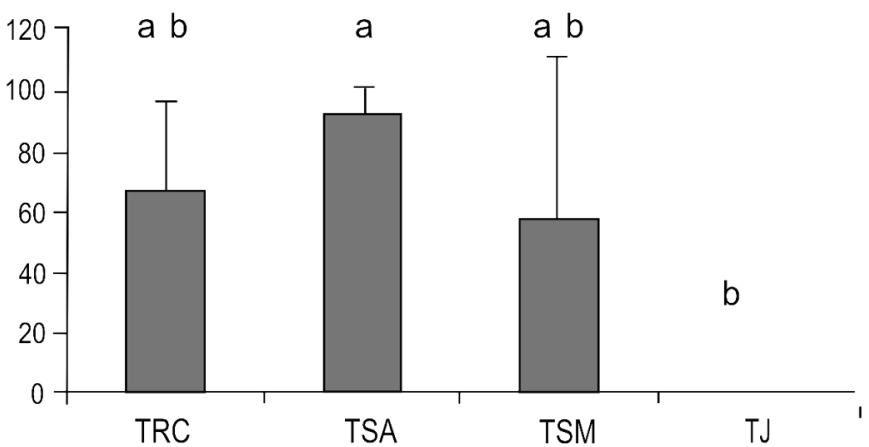

\section{RESULTADOS E DISCUSSÃO}

Os resultados encontrados dos parâmetros de água dos recipientes como $\mathrm{pH}$, oxigênio dissolvido e temperatura foram de $6,97 \pm 0,04,5,28 \pm 1,31 \mathrm{mg} / \mathrm{L}$ e $29,64 \pm 0,39^{\circ} \mathrm{C}$, respectivamente, e comprovam a não interferência da qualidade da água na manutenção destes animais na condição experimental do presente trabalho, permanecendo dentro dos padrões adequados para criação dos peixes (Sipaúba-Tavares 1995).

Os parasitas encontrados nos peixes utilizados nos tratamentos foram identificados como larvas de Capillaria sp., larvas da família Anisakidae, e um gênero de monogenético (Urocleidoides sp.).

Após o período experimental, pôde-se verificar que os peixes dos tratamentos TJ e TSM foram os que apresentaram maior perda media de peso, $39 \%$ e $25 \%$, respectivamente (figura $1 \mathrm{~A})$. A perda media de peso no TSM (25\%), sugere pouca palatabilidade, evidenciado pelas sobras de ração observadas durante o experimento. Essa perda de peso associada a um baixo consumo de ração influenciou diretamente na eficácia desse tratamento, uma vez que não foram observadas diminuições evidentes de parasitos encontrados no estômago e no intestino para os peixes do TSM (Fig.1B e 1C, respectivamente).

Observou-se, porém, uma maior eficácia no controle de nematóides, no estômago e no intestino (95,26\% e

\section{Capillaria sp. e Anisakidae no estômago}
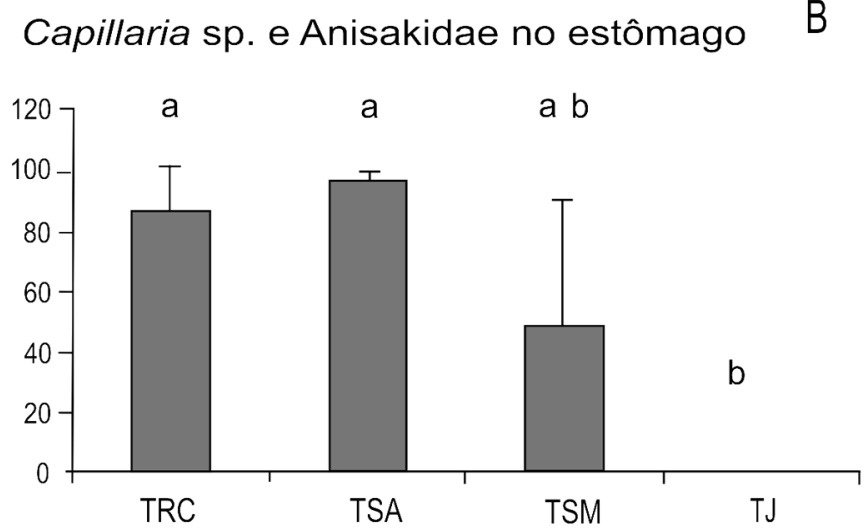

Urocleidoides sp.

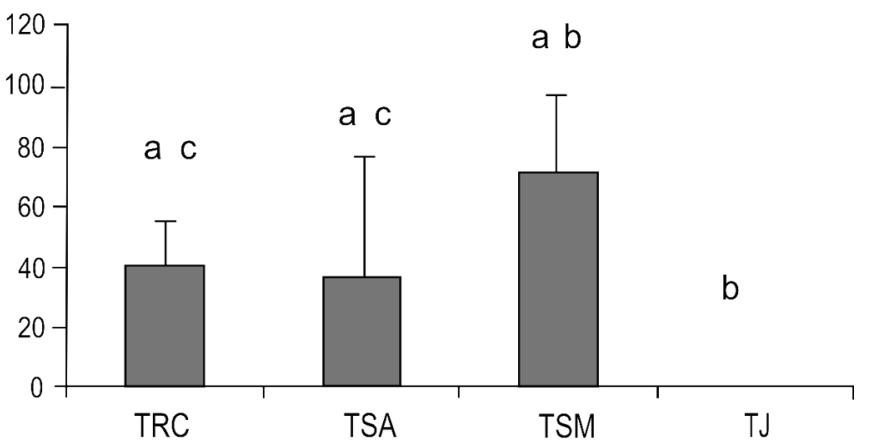

Fig.1. (A) Perda de peso em porcentagem; (B) Eficácia contra Capillaria sp. e Anisakidae no estômago; (C) Capillaria sp. e Anisakidae no Intestino e (D) monogenético, helmintos parasitos de Astyanax cf. zonatus. Animais tratados em jejum (T)), com ração comercial (TRC), sementes de abóbora (TSA) e semente de mamão (TSM). As letras indicam os resultados de comparação de media obtido pelo teste de Tukey $(\mathrm{p}<0,05)$. 
$92,48 \%$ ), quando os peixes foram alimentados com as sementes de abóbora (TSA) $(p<0,05)$ (Fig.1B,C), demonstrando sua ação como anti-helmíntico. Outra ação da semente de abóbora foi encontrada por Albuquerque (2004), afirmou que foi eficaz em sua ação nematicida no tratamento de nematóides de répteis (Chenopodium ambrosioides).

Segundo Guarrera (1999) a propriedade anti-helmíntica presente nas sementes de abóbora é atribuída ao principio ativo denominado cucurbitina, porém Obregón et al. (2004) afirmaram que é a Fitosterolina é que provoca a morte do parasito, porém no presente trabalho não foram analisadas a presença de nenhum dos dois princípios. Coimbra et al. (2006) ressaltaram que uma das vantagens de se usar os fitoterápicos é que eles possuem modos de ação diversos, podendo conter diferentes princípios ativos atuando em diferentes parasitas, e que desse modo diminui-se a probabilidade de causar resistência do parasita.

Interessante notar que os peixes do grupo TRC apresentaram diminuição dos parasitos, representado no presente estudo como eficácia, porém, sugere-se que isso ocorre não pelo fato de a ração causar danos aos parasitos, mas provavelmente devido a melhora nas condições fisiológicas após a alimentação com ração comercial, pois o estado nutricional influencia na condição sanitária dos peixes predispondo ou não a doenças (Pickering \& Pottinger 1985, Pickering \& Pottinger 1989, Maule et al. 1993). Além disso, os nematóides necessitam de um hospedeiro intermediário para completar o ciclo de vida, dessa forma, a manutenção dos peixes em condições isentas de hospedeiros intermediários (zooplâncton) e a alimentação com a ração comercial pode-se ter quebrado esse ciclo impedindo novas reinfestações. Segundo Martins et al. (2007), a presença de microcrustáceos como primeiro hospedeiro intermediário do nematóide do gênero Camallanus $s p$. causam impactos negativos nos cultivos de peixes devido a essa parasitose.

No Tratamento com sementes de mamão (TSM) foi observado menor valor de eficácia para nematóides do estômago $(48,41 \%)$ e intestino $(59,42 \%)$ (figura $1 \mathrm{~B}$ e $1 \mathrm{C}$ ), estes valores contrastaram com os resultados obtidos por vários autores. Auró (2004), verificou que sementes de mamão foram eficazes no tratamento de Tilápia (Oreochromis niloticus) contra nematóides do gênero Cucullanus sp. Satrija et al. (1994) avaliou o efeito anti-helmintico do leite de mamão no tratamento contra Ascaris suum, chegando até a negativação dos resultados parasitológicos em um dos tratamentos (8g de leite/ $\mathrm{kg}$ de peso corporal). Mpoame \& Essombra (2000), também observaram a eficiência do tratamento utilizando extrato aquoso de sementes de mamão contra nematóides dos gêneros Heterakis, Eimeria e Capillaria, em frango de corte, sendo que para os dois primeiros gêneros foi constatada grande diminuição do número de nematóides, enquanto que sobre Capillaria não foi observada ação parasiticida. 0 que pode corroborar os achados do presente trabalho na medida em que os nematóides encontrados pertenciam também ao gênero Capillaria. Essa ação nematicida do mamão também foi verificada em nematóides parasitas de plantas, onde Coimbra et al. (2006) verificou mortalidade de $67,2 \%$ do fitonematoide (Scutellonema bradys) parasita de inhame (Dioscorea cayennensis) quando utilizou extrato aquoso da semente e da folha do mamoeiro.

No presente trabalho não foi observado essa ação nematicida no TSM, corroborando com os resultados obtidos por Krychak-Furtado (2005), que também não observou ação das sementes de mamão contra nematóides gastrointestinais no tratamento de ovinos. Como sugerido acima para a perda de peso as sementes de mamão não foram totalmente consumidas o que pode ter influenciado negativamente na eficácia contra os endoparasitas do presente trabalho.

No entanto, para o controle de monogenético apenas o TSM apresentou uma eficácia de 72\% (Fig.1D), enquanto que nos outros tratamentos não foi observada uma eficácia relevante. Isso sugere a possível existência de substância química sendo liberada na água, que provocaria a morte desses parasitas presentes nas brânquias. Essa solubilidade em água foi sugerida por Vieira et al. (1999), quando estes se referiram à administração de sementes de mamão trituradas, misturadas em água e fornecendo este extrato aquoso no tratamento de nematóides de cabras. Coimbra et al. (2006) também estudaram o efeito do extrato aquoso de semente de mamão sobre o nematóide Scutellonema bradys parasito de vegetais tubérculos, mostrando efeito nematostático e nematicida. Kermanshai et al. (2001) utilizando solventes orgânicos, separaram a substância química benzilisotiocianato a partir de extratos aquosos de sementes de mamão, e segundo estes autores este seria o princípio ativo da ação anti-helmintica da semente, sendo que 10-20 $\mu \mathrm{L}$ do extrato aquoso com semente de mamão, provocou mortalidade superior a $90 \%$ do helminto Caenorhabditis elegans.

Com relação à análise de leucócitos, somente observou-se diferença significativa nos eosinófilos e nos monócitos ( $\mathrm{p}<0,05)$ (Fig.2B,C). Segundo Queiroz-Neto et al. (1994) a administração oral de sementes secas de Cucurbita maxima não afeta os parâmetros contagem de células sanguíneas e não apresenta toxicidade em ratos e suínos.

Quanto à presença de linfócitos podemos destacar que em todos os tratamentos foi observada abundância destas células (Fig.2A), segundo Tavares-Dias et al. (2002) estas células são as mais freqüentes no sangue periférico dos peixes. Ranzani-Paiva et al (2004), também afirmaram que estas células são o tipo mais freqüente de leucócitos circulantes de peixes, e que uma linfocitopenia poderia ser uma resposta a um agente estressante, devido ao aumento de cortisol provocando uma diminuição das capacidades dos peixes em se defender contra potencias agentes patogênicos (Pickering \& Pottinger 1985). Essa diminuição foi observada no tratamento com semente de mamão, porém não foi significativa.

Com relação aos eosinófilos (Fig.2B), os peixes que ficaram em jejum e que apresentaram maior quantidade de parasito apresentaram maior quantidade destas células em relação aos outros tratamentos. Isso ocorre pois os eosinófilos são células atuantes na resposta à presença de parasitas e nas reações alérgicas (Tavares-Dias \& Moraes 2004). Nos demais tratamentos onde houve o controle dos parasitas, o número destas células diminuiu. Essa diminuição de eosinofilos também foi relatada em carpas por Ranzani-Paiva et al. (1987) quando o numero de parasitas Argulus sp. diminuiu, após o tratamento químico com Neguvon (fosfato de 0,0-dimentil-oxi-2,2,2-tricloroetilo). 
Linfocitos $\quad$ E Esinofilos
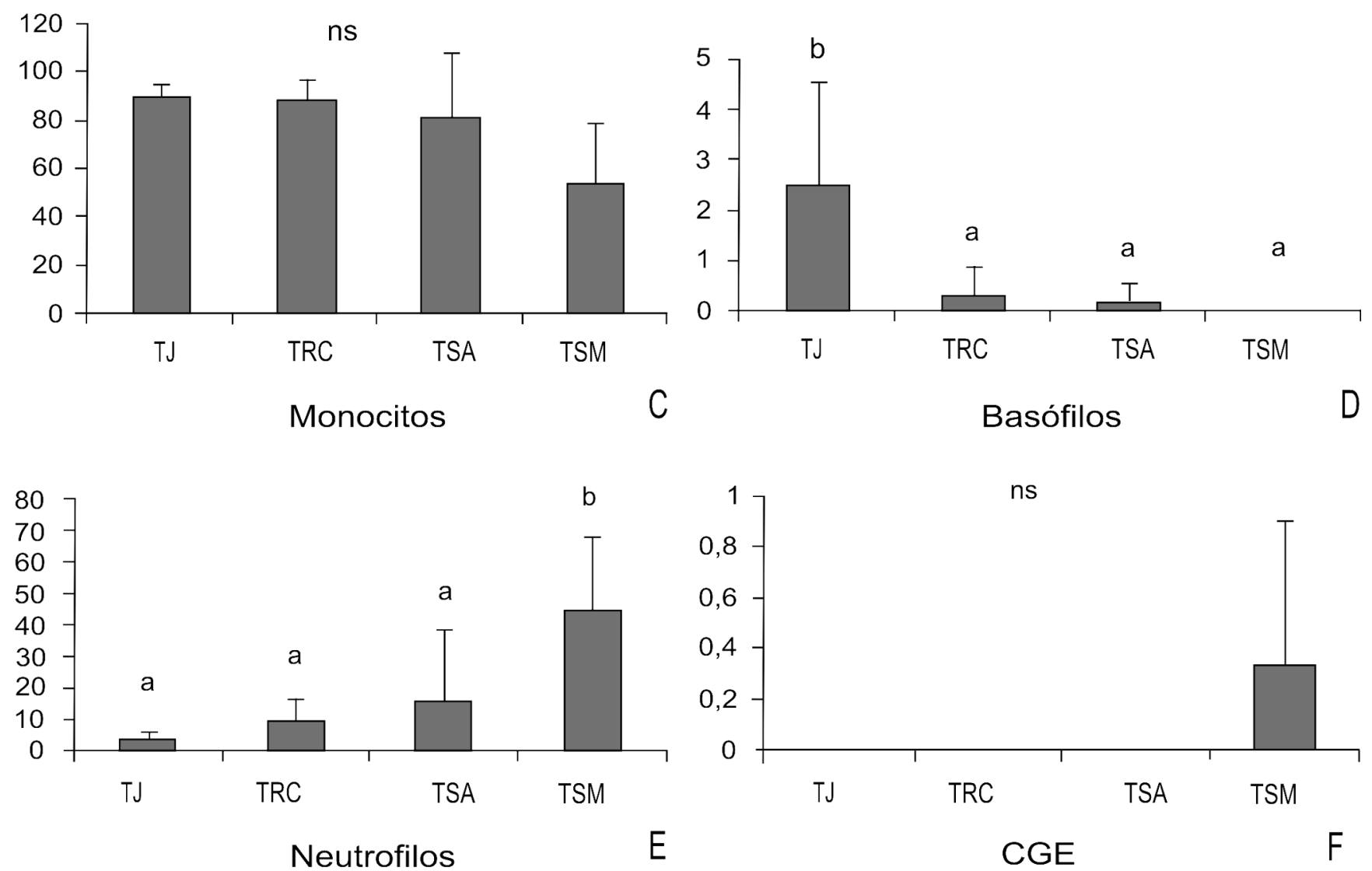

Neutrofilos

$E$

ns
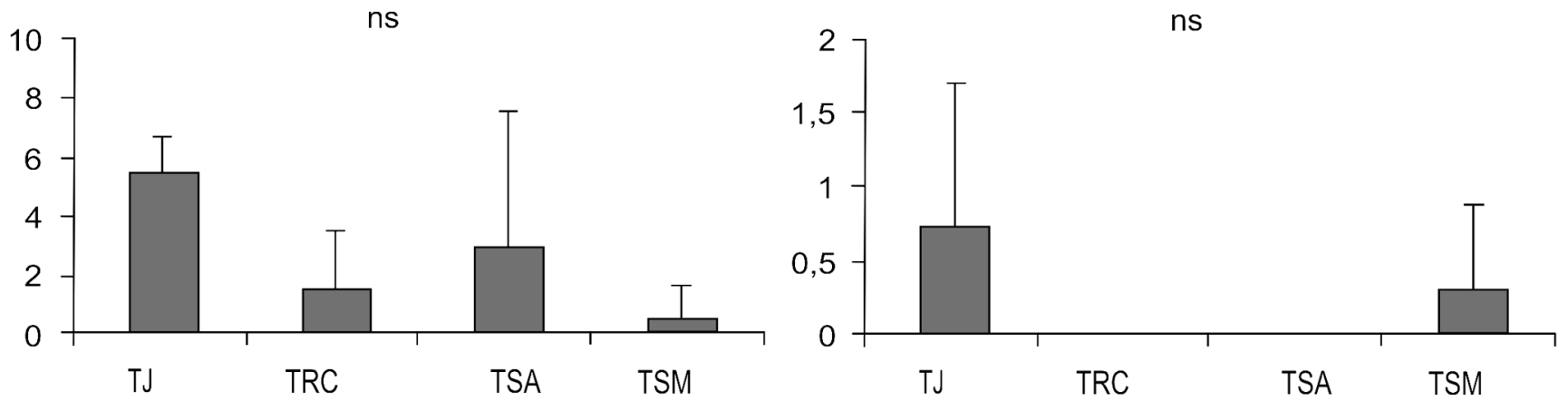

Fig.2. Valores médios percentuais da contagem diferencial de leucócitos em Astyanax cf. zonatus, tratados em jejum (TJ), com ração comercial (TRC), sementes de abóbora (TSA) e semente de mamão (TSM).

Observou-se também uma diferença entre os valores encontrados de monócitos para os tratamentos dos peixes alimentados com semente de mamão e os demais tratamentos, sendo que os peixes no tratamento com mamão apresentaram os maiores valores (44,66\%). Pimpão (2006) afirmou que, monócitos, são consideradas células de alarme responsáveis pelo inicio da migração dos neutrófilos, sugerindo que provavelmente estaria no inicio do processo de mobilização dos neutrófilos.

\section{CONCLUSÕES}

O método de controle utilizando sementes de abóbora mostrou-se eficaz contra nematóides no estômago e intestino, além de baixo custo e praticidade.
A alimentação com semente de mamão foi a única a demonstrar eficiência no combate a monogenéticos, sugerindo um efeito a partir de extratos aquosos, porém sua eficácia não foi acima de $90 \%$.

Agradecimentos. - Ao Conselho Nacional de Desenvolvimento Científico e Tecnológico (CNPq) pela concessão de bolsa de mestrado. E ao apoio da Pró-Reitoria de Pesquisa e Pós-Graduação da Universidade Federal do Pará (PROPESP/UFPA) e da Fundação de Amparo e Desenvolvimento da Pesquisa (FADESP).

\section{REFERÊNCIAS}

Abdallah V.D., Azevedo R.K. \& Luque J.L. 2004. Metazoários parasitos dos lambaris Astyanax bimaculatus (Linnaeus, 1758), A. parahybae (Eigenmann, 1908) e Oligosarcus hepsetus (Cuvier, 1829) (Osteichthyes: cha- 
racidae), do rio Guandu, Estado do Rio de Janeiro, Brasil. Revta Bras. Parasitol. Vet. 13(2):57-63.

Albuquerque H.N., Albuquerque I.C.S., Monteiro J.A., Barbosa A.R., Sousa M.S. \& Cavalcanti M.L.F. 2004. Uso de plantas medicinais no tratamento de répteis em cativeiro: um estudo preliminar. Revta Biol. Ciênc. Terra. 4:1-9.

Amato J.R.F., Boeger W.A. \& Amato S.B. 1991. Protocolos para laboratórios: coleta e processamento de parasitas e pescados. Imprensa Universitária da UFRRJ, Rio de Janeiro. 81p.

Auró O.A \& Campo C.L. 2003. Evaluación comparativa del efecto profilático del ajo y de um producto de patente contra gram negativa em tilapia (Oreochromis hornorum). TIP Revta Especializada en Ciencia Quimico-Biológicas 6(2):67-73.

Chagas A.C.S. 2004. Controle de parasitas utilizando extratos vegetais. Revta Bras. Parasitol. Vet 13(1):156-160.

Coimbra J.L., Soares A.C.F., Garrido M.S., Souza C.S. \& Ribeiro F.L.B. 2006. Toxicidade de extratos vegetais a Scutellonema bradys. Pesq. Agropec. Bras. 41(7):1209-1211.

Cruz C., Machado-Neto J.G. \& Menezes M.L. 2004. Toxicidade aguda do inseticida paration metílico e do biopesticida azadiractina de folhas de neem (Azadirachta indica) para alevino e juvenil de pacu (Piaractus mesopotamicus). Pesticidas. Revta Ecotoxicologia Meio Ambiente, Curitiba, 14:93-102.

FDA (US Food and Drugs Administration) 1998. Certain other from new animal drugs; Formalin Solution. Code of federal regulations, 21CFR. Washington, DC.

FDA (US Food and Drugs Administration) 1992. Requirements for investigational new animal drugs. Eastern Fish Health Group and the American Fisheries Society Fish Health. The FDA Workshop, Auburn, Alabama.

Ghiraldelli L., Martins M.L., Yamashita M.M. \& Jerônimo G.T. 2006. Ectoparasites influence on the haematological parameters of Nile tilapia and carp cultured in the State of Santa Catarina, South Brazil. J. Fish. Aquatic Sci. 1(3):270-276.

Guarrera P.M, 1999. Traditional antihelmintic, antiparasitic and repellent uses of plants in Central Italy. J. Ethnopharmacol. 68:183-192.

Hirazawa N., Ohtaka T. \& Hata K 2000. Challenge trials on the anthelmintic effect of drugs and natural agents against the monogenean Heterobothrium okamotoi in the tiger puffer Takifugu rubripes. Aquaculture 188:1-13.

Kermanshai R., Mccarry B.E., Rosenfeld J., Summers P.S., Weretilnyk E.A. \& Sorger G.J. 2001. Benzyl isothiocyanate is the chief or sole anthelmintic in papaya seed extracts. Phytochemistry 57:427-35.

Krychak-Furtado S., Negrelle R.B., Miguel O.G., Zaniolo S.R., Kapronezai J., Ramos S.J. \& Sotello A. 2005. Efeito de Carica papaya L. (Caricaceae) e Musa paradisiaca L. (Musaceae) sobre o desenvolvimento de ovos de nematódeos gastrintestinais de ovinos. Arqs Inst. Biológico, São Paulo, 72(2):191-197.

Martins M.L. 2004. Cuidados básicos e alternativas no tratamento de enfermidades de peixes na aqüicultura brasileira, p.357-370. In: Ranzani-Paiva M.J., Takemoto R.M. \& Lizama M.A.P. (Eds), Sanidade de Organismos Aquáticos. Editora Varela, São Paulo.

Martins M.L., Onaka E.M., Moraes F.R. \& Fujimoto R.Y. 2001. Mebendazole treatment against Anacanthorus penilabiatus (Monogenea, Dactylogyridae) gill parasite of cultivated Piaractus mesopotamicus (Osteichthyes, Characidae) in Brazil: Efficacy and hematology. Acta Parasit. Port. 46(4):332-336.

Martins M.L., Ghiraldelli L., Garcia F., Onaka E.M. \& Fujimoto R.Y. 2007. Experimental infection in Notodiaptomus sp. (Crustacea: Calanoida) with larvae of Camallanus sp. (Nematoda: Camallanidae). Arq. Bras. Med. Vet. Zootec. 59(2):382-386.

Maule A., Schereck C. \& Sharpe C. 1993. Seasonal changes in cortisol sensitivity and glucocorticoid receptor affinity and number in leukocytes of coho salmon. Fish Physiol. Biochem. 10:497-506.
Morais S.M., Dantas J.D.P., Silva A.R.A. \& Magalhães E.F. 2005. Plantas medicinais usadas pelos índios Tapebas do Ceará. Revta Bras. Farmacogn. 15:169-177.

Mpoame M. \& Essomba L.I. 2000. Treatment of gastrointestinal parasitoses of chickens with aqueous decoctions of papaya (Carica papaya) seeds. Revue d'Élevage et de Médecine Vétérinaire des Pays Tropicaux 53(1):23-25.

Navarro R.D., Silva R.F., Ribeiro Filho O.P., Calado L.L., Rezende F.P., Silva C.S. \& Santos L.C. 2006. Comparação morfometrica e índices somáticos de machos e fêmeas do lambari prata (Astayanax scabripinnis Jerenyns, 1842) em diferente sistema de cultivo. Zootec. Trop, 24(2):165-176.

Obregón D.D., Lozano L.L. \& Zúñiga V.C. 2004. Estudios preclínicos de cucurbita maxima (semilla de zapallo) un antiparasitario intestinal tradicional em zonas urbano rurales. Revta Gastroenterol. 24:323-327.

Pickering A.D. \& Pottinger T.G. 1985. Cortisol can increase the susceptibility of brown trout, Salmo trutta L., to disease without reducing the white blood cell count. J. Fish Biol. 27:611-619.

Pickering A.D. \& Pottinger T.G. 1989. Stress response and disease resistance in salmonid fish: effects of chronic elevations of plasma cortisol. Fish Physiol. Biochem. 7:253-258.

Pimpão T.C. 2006. Avaliação aguda dos efeitos toxicológicos da deltametrina em uma espécie de peixe fluvial nativo: estudo bioquímico e imunotóxico. Tese de Doutorado, Universidade Federal do Paraná, Curitiba. 102p.

Queiroz-Neto A., Mataqueiro M.I., Santana A.E. \& Alessi A.C. 1994. Toxicologic evaluation of acute and subacute oral administration of Cucurbita maxima seed extracts to rats and swine. J. Ethnopharmacol. 43(1):45-51.

Ranzani-Paiva M.J.T., Ishikama L.M., Portell M.C. \& Celiberto R.J. 1987. Hematologia da carpa comum Cyprinus carpio, infestada por Argulus sp. e após um tratamento com fosfato de 0,0-dimentil-oxi-2,2,2-tricloroetilo (Neguvon). Bolm. Inst. Pesca 14:83-92.

Ranzani-Paiva M.J.T. \& Silva-Souza A.T. 2004. Hematologia de Peixes Brasileiros, p.89-120. In: Ranzani-Paiva M.J.T., Takemoto R.M. \& Lizama M.L.A.P. (Eds), Sanidade de Organismos Aquáticos. Editora Varela, São Paulo.

Reardon I.S. \& Harrell R.M. 1990. Acute toxicity of formalin and copper sulfate to striped bass fingerlings held in varying salinities. Aquaculture, Amsterdam, 87:255-270.

Rosenfeld G. 1947. Corante pancrômico para hematologia e citologia clínica: nova combinação dos componentes do May-Grünwald e do Giemsa num só corante de emprego rápido. Mem. Inst. Butantan, São Paulo, 20:329-334

Santin M., Di Benedetto M., Bialetzki A., Nakatani K. \& Suiberto M.R. 2005. Aspectos da dieta de larvas de Astyanax janeiroensis (Eigenmann, 1908) (Osteichthyes, Characidae) no reservatório de Uaricana, Rio Arraial, Estado do Paraná. Bolm Inst. Pesca, São Paulo, 31(1):73-80.

Satrija F., Nansen P., Bjorn H., Murtini S. \& He S. 1994. Effect of papaya latex against Ascaris suum in naturally infected pigs. J. Helmintol. 68:343-346.

Sipaúba-Tavares L.H. 1995. Limnologia Aplicada à Aqüicultura. Funep, Jaboticabal. 70p.

Tavares-Dias M. 2000. Estudos parasitólogico e hematológico em peixes oriundos de "pesque-pagues" do município de Franca, São Paulo. Dissertação de Mestrado, Universidade Estadual Paulista, São Paulo,SP.

Tavares-Dias M. \& Moraes F.R. 2004. Hematologia de peixes teleósteos. Villimpress, Ribeirão Preto, SP. 144p.

Tavares-Dias M., Martins M.L., Schalch S.H.C., Onaka E.M., Quintana C.I.F., Moraes J.R.E. \& Moraes F.R. 2002. Alterações hematológicas e histopatológicas em pacu, Piaractus mesopotamicus Holmberg, 1887 (Osteichthyes, Characidae), tratado com sulfato de cobre (CuSO4). Acta Scientiarum 24(2):547-554.

Vieira L.S., Cavalcante A.C.R., Pereira M.F., Dantas L.B. \& Ximenes L.J.F. 1999. Evaluation of anthelmintic efficacy of plants available in Ceará State, North-East Brazil, for the control of goat gastrointestinal nematodes. Revta Bras. Med. Vet. 150(5):447-452. 